\title{
Technology Acceptance and User-Centred Design of Assistive Exoskeletons for Older Adults: A Commentary
}

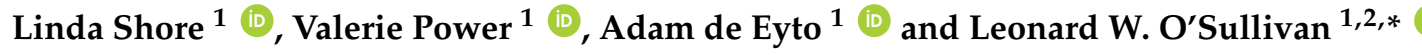 \\ 1 School of Design, University of Limerick, V94 T9PX Limerick, Ireland; Linda.shore@ul.ie (L.S.); \\ Valerie.power@ul.ie (V.P.); Adam.deeyto@ul.ie (A.d.E.) \\ 2 Health Research Institute \& School of Design, University of Limerick, V94 T9PX Limerick, Ireland \\ * Correspondence: Leonard.osullivan@ul.ie; Tel.: +353-61-234249
}

Received: 5 September 2017; Accepted: 27 December 2017; Published: 3 January 2018

\begin{abstract}
Assistive robots are emerging as technologies that enable older adults to perform activities of daily living with autonomy. Exoskeletons are a subset of assistive robots that can support mobility. Perceptions and acceptance of these technologies require understanding in a user-centred design context to ensure optimum experience and adoption by as broad a spectrum of older adults as possible. The adoption and use of assistive robots for activities of daily living (ADL) by older adults is poorly understood. Older adult acceptance of technology is affected by numerous factors, such as perceptions and stigma associated with dependency and ageing. Assistive technology (AT) models provide theoretical frameworks that inform decision-making in relation to assistive devices for people with disabilities. However, technology acceptance models (TAMs) are theoretical explanations of factors that influence why users adopt some technologies and not others. Recent models have emerged specifically describing technology acceptance by older adults. In the context of exoskeleton design, these models could influence design approaches. This article will discuss a selection of TAMs, displaying a chronology that highlights their evolution, and two prioritised TAMs-Almere and the senior technology acceptance model (STAM) - that merit consideration when attempting to understand acceptance and use of assistive robots by older adults.
\end{abstract}

Keywords: assistive robots; technology acceptance; mobility assistance; user-centred design

\section{Introduction}

Older adults (aged 65+) are expected to account for at least $25 \%$ of the European population by 2020, increasing to $40 \%$ between the years of 2010-2030 [1]. Globally, disability rates in adults aged $60+$ have been recorded as $43.4 \%$ in lower income countries and $29.5 \%$ in higher income countries [2]. Assistive technology (AT) devices can offer improved quality of life to older adults, with robotics offering new directions within the field of AT [3]. In 2013, approximately $13 \%$ of the population in the United States of America were living with a mobility impairment, which is considered the most prevalent disability [4]. In 2015, there were over 20 million people living in the USA with an ambulatory disability [5]; globally, this figure exceeds a billion people [2]. In Europe, approximately 80 million people live with some form of disability [6]. Disability in older adults commonly manifests itself as mobility impairment experienced in daily life. Disabled older adults experience higher rates of illness, reduced quality of life and social isolation [7].

Exoskeletons are rapidly gaining in prominence as an assistive technology; the wearable robots and exoskeleton market is forecast to be worth US \$2.1Bn by the year 2021 [8]. However, as an emerging technology, there is still a lack of robust quantitative evaluations of their performance [9]. In addition, relatively little is known about older adults' opinions on using exoskeletons, or assistive robots 
in general, for daily tasks in the home [10,11]. Issues with adoption and acceptance may be expected, since some older adults are slower to adopt and use new technologies compared to younger people [12]. Therefore, research providing user insights may be useful to help understand and optimise the acceptance and adoption of such devices by older adults.

Nathan [13] discussed the emerging opportunities for exoskeletons in medical and consumer applications. Assistive robots [14] have been introduced as aids in manipulation, mobility and cognition contexts. Exoskeletons can offer support for older adults to remain independent as they engage in activities of daily living (ADLs) [10,15-17]. At a physical level, assistive robot interventions can maintain body movement and provide motivation for older adults to remain active. At a social level, when users are able to respond and make eye contact as a result of being upright, it may result in greater autonomy and independence as they participate in social and leisure activities, thus reducing the likelihood of depression or social isolation $[18,19]$. There is a significant market, and strong social and design opportunities for assistive consumer exoskeletons that can support older adults and enhance quality of life [10]. For exoskeletons to penetrate the consumer market segments, they must meet essential user expectations in order for older adults to accept and adopt them in their daily lives.

However, exoskeleton technologies remain primarily focused on rehabilitation, and military and industry applications $[9,14]$. There are many challenges with exoskeleton design to be solved before they become a part of mainstream daily living [4,9] (e.g., outside the home, with a companion, and in training to use the device [4]). As complex wearable systems, there are several potential barriers to the adoption of exoskeletons in daily life such as stigma, technology anxiety and fear of dehumanizing society $[17,20]$.

Hill et al. [21] state that enquiry to gauge user perspectives of exoskeleton technology is minimal, with no literary evidence of user involvement in the development or design of exoskeletons. Wolff et al. [22] surveyed wheelchair users and healthcare professionals about their opinions of exoskeleton use. The primary reasons cited for adopting an exoskeleton were around health benefits. As part of the study, they also reported on important design-related aspects that should be considered, in particular, minimising the risk of falls (when wearing an exoskeleton), comfort in use, ease of putting on and taking off, and cost. They projected a need for exoskeleton design to specifically focus on the following:

- Robust control

- Safety and dependability

- Ease of wear ability/portability

- Usability/acceptance

Older adults highlight the importance of maintaining independence with regard to their quality of life as they age; technology products can be critical to enhancing and maintaining autonomy if faced with a disability [23]. Gerontechnology is intended to deliver solutions that impact and assist older adults as they engage with technologies to maintain or improve health and independent living [19]. From a design perspective, gerontechnology relates to understanding older adults' experiences and barriers to using technologies. When applied successfully, technology acceptance by the target group of older adult users can be achieved. It is important that older adults do not feel overwhelmed or intimidated by the complexity of an assistive robot, or find it frustrating to use, thereby demotivating them $[17,24]$. These negative experiences may ultimately result in abandonment.

Randolph and Hubona [25] discuss the perspectives and varying needs that people with disabilities have when adopting and using new technologies. They state how ability is measured and easily assessed, but that the skill to use technology can be more ambiguous, and not so easy to predict. This presents a challenge to the design of exoskeletons, which are still an emerging technology, but in the coming years may be worn by people in social and community settings [9].

Exoskeletons have potential applications in a wide variety of environments aside from healthcare, and where they are not necessarily classified as medical devices [26] or for use by people with 
disabilities. Technology acceptance in relation to exoskeletons must be considered in broader terms than typical frameworks by which assistive technology is prescribed for patients, such as the International Classification of Functioning Disability \& Health (ICF, 2001) [27], the Human Activity Assistive Technology (HAAT) model [18] or Matching Person and Technology model (MPT) [28]. These models are acknowledged as user-focussed, and are for assessment by collaboration between the user and their health professional to determine suitability for assistive technologies. The concept of assessing person-environment-technology interaction developed as a result of concern about AT abandonment rates, and commentary expressing how a multi-disciplinary approach to assessing and understanding user needs can reduce AT abandonment [28]. There is a need to explore other frameworks and tools that assist with understanding users' perceptions of assistive exoskeletons and implementing acceptance criteria in the design of such devices.

Technology acceptance models (TAMs) have evolved to describe users' acceptance of technological applications [29] and are tools to relate users' intended use with their actual use of devices [30]. The purpose of this article is to comment on a literature review of TAMs applicable to exoskeleton technologies, in particular for older adults. The commentary highlights the importance of user-centred design in technology acceptance, and how the exoskeleton design life cycle should take into account and apply recommended design guidance in this regard.

\section{Technology Acceptance Models}

TAMs are theoretical approaches to describe factors that affect user acceptance of technologies [29]. They can also be used to describe factors that explain users' intentions to use a device [30]. More recent developments of technology acceptance models specifically gauge acceptance by older adults of technology devices, e.g., computers, mobile phones, assistive social robots (Almere [30] \& STAM [31]).

We performed an analysis of the literature for technology acceptance models and provide a narrative review of the key models identified, including a chronological positioning of the main developments (Figure 1). This section will discuss these models and their evolution, culminating in models of technology acceptance by older adults.

The review identified six models, which are summarised in Figure 1 and listed below. These models are described in the subsequent sections.

- $\quad$ Theory of reasoned action [32]

- Theory of planned behaviour [33]

- Technology acceptance model [34]

- Unified theory of acceptance and use of technology [35]

- $\quad$ The Almere model [30]

- Senior technology acceptance model [31]

\subsection{Theory of Reasoned Action (TRA)}

Azjen and Fishbein (1980) [32] presented the theory in which people consider consequences or implications of decisions they make before engaging in a behaviour (Figure 2). The theory of reasoned action presents the idea that two factors influence the intention of the person: personal motivation (attitude toward the behaviour) and social influences that determine motivation to perform the behaviour (subjective norm). The model distinguishes between beliefs, attitudes, intentions and behaviours as a means to assess a person's attitude. 


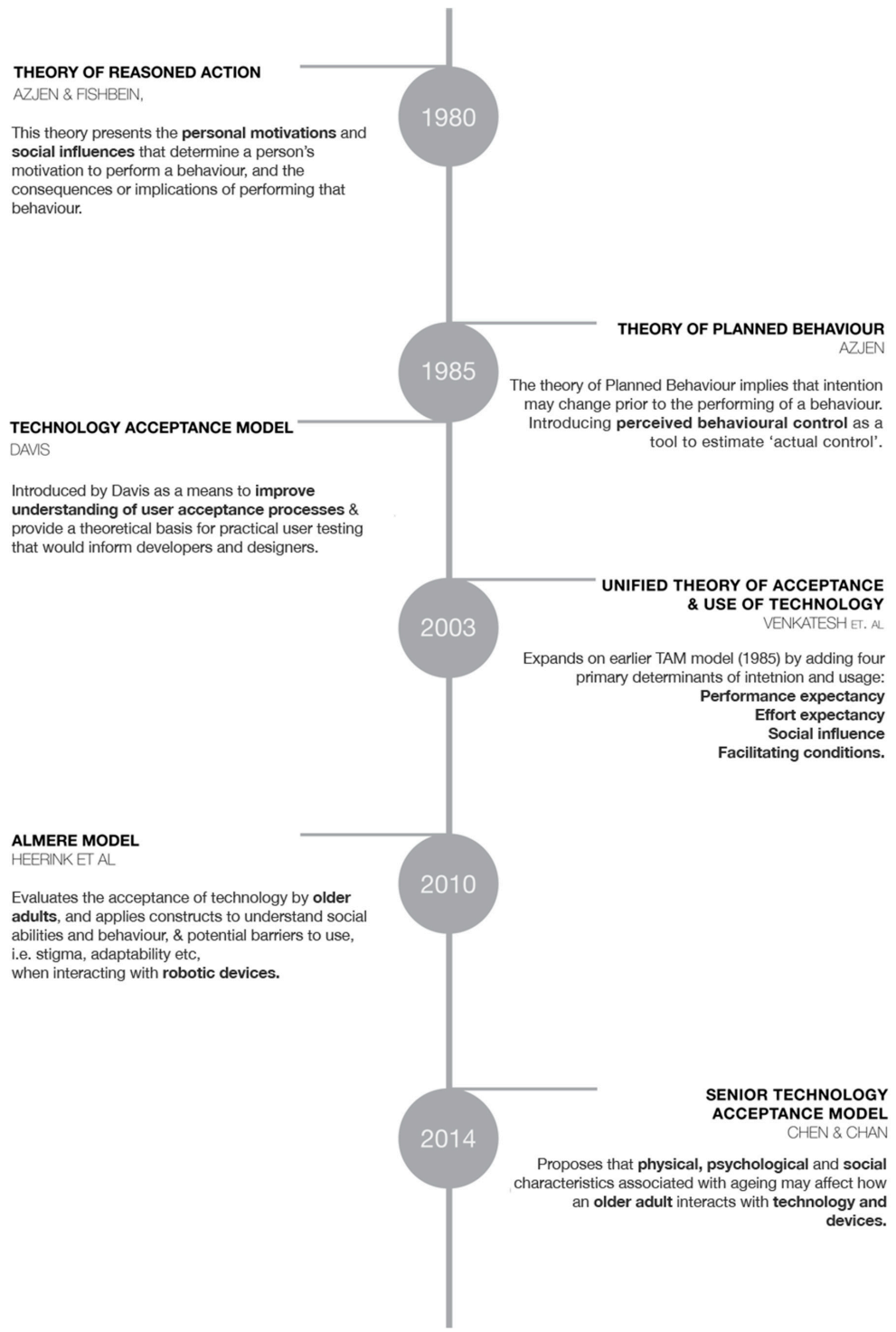

Figure 1. Chronology of selected technology acceptance models, highlighting their development and evolution to include older adults and technology devices.

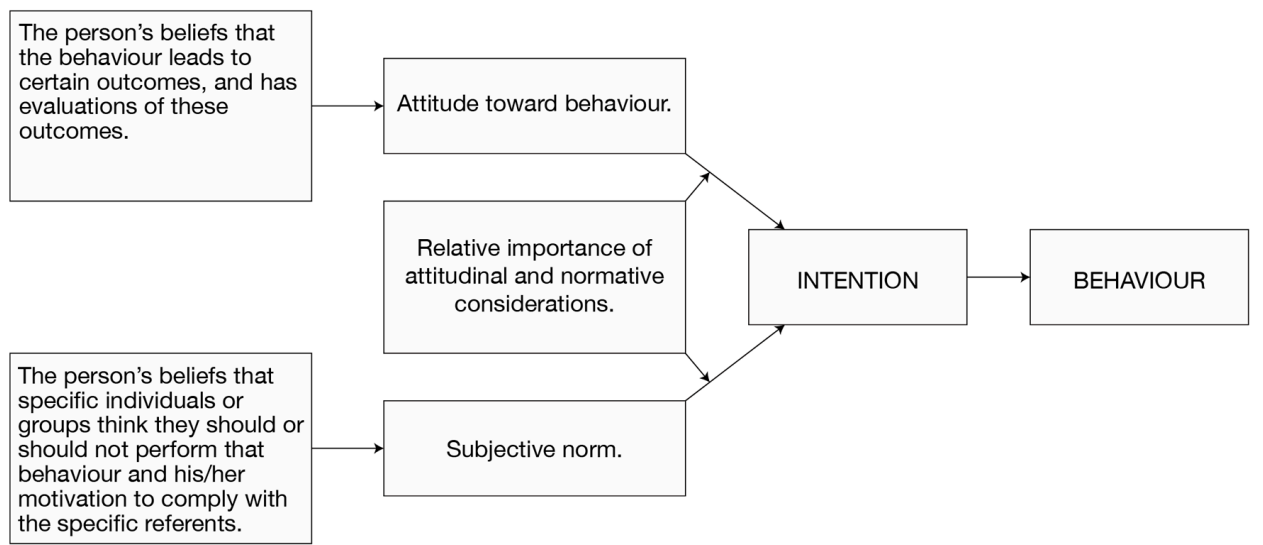

Figure 2. Ajzen and Fishbein present the idea that people consider consequences or implications of decisions they make before engaging in a 'behaviour'. The above figure displays the factors that determine a person's behaviour, as per the theory of reasoned action [32]. 


\subsection{Theory of Planned Behaviour (TPB)}

The theory of planned behaviour, by Ajzen [33], extended previous work to include the construct of 'attempt' to perform the behaviour, and that 'intention' should be noted with the awareness that factors outside the control of a person may impact or change the person's intention to successfully perform the behaviour. This presents a need to incorporate the beliefs and attitudes towards trying, as well as a behaviour's success or failure. Perceived behavioural control is discussed in the theory as offering insight into understanding a person's motivation and self-efficacy/awareness of consequences of success and failure of a particular behaviour.

\subsection{Technology Acceptance Model (TAM)}

Davis [34] proposed the first model labelled a technology acceptance model (Figure 3) and is regarded as authoring the seminal work on this topic. Davis introduced the concepts of perceived usefulness (PU) and perceived ease of use (PEOU). Figure 3 displays the various responses to the example design features that are generically displayed as $\mathrm{X} 1, \mathrm{X} 2$ and $\mathrm{X} 3$ and their causal relationships to the potential user's overall attitude towards using a system. A few years later, Davis [36] acknowledged the influence of self-efficacy on both of these factors. The model indicates how design features relate to cognitive responses (PU and PEOU), which result in an affective and behaviour response. As such, it specifically highlights the role of design features in this regard.

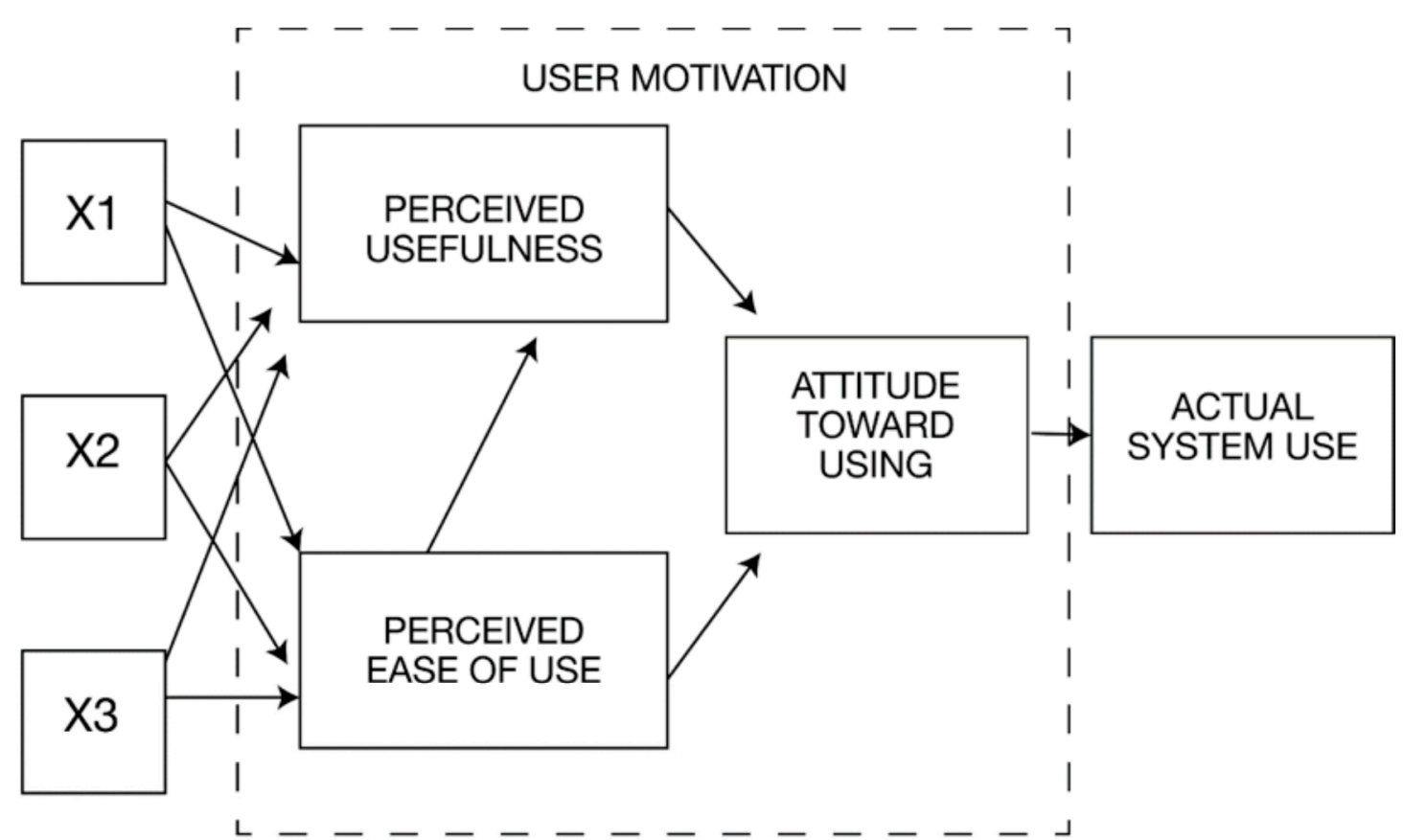

\section{Design \\ Cognitive \\ Affective Response \\ Behavioural Response}

Figure 3. Technology acceptance model (TAM) displaying the various responses and the constructs of TAM affected by the design features that are displayed as examples, and stated as X1, X2 and X3 [34].

Davis also proposed a generic user acceptance testing process, which is not routinely detailed in TAM models. The acceptance testing method (Figure 4) uses four sub-procedures: opportunity scanning, functional screening, interface screening, and prototype testing [34]. These four sub-procedures offer direct insights for exploring acceptance of technology by highlighting the importance of awareness of new and emerging technologies. Davis (1985) suggests how the TAM 
might be applied in design settings in relation to the overall design approach. Furthermore, the type of testing, by way of hands-off (verbal descriptions, slide presentations, video) versus hands-on testing (user interaction with test systems) is considered. The model specifically stresses the role of prototype testing and refinement regarding user requirements. It is notable how TAM, at this time, was directed towards systems and technology applications in a workplace setting, and not in a social or domestic environment. This, in turn, presents a question to understand how TAM can be applied with consideration to technology acceptance of people in a domestic setting using assistive devices to support ADLs [15].

\section{OPPORTUNITY SCANNING}

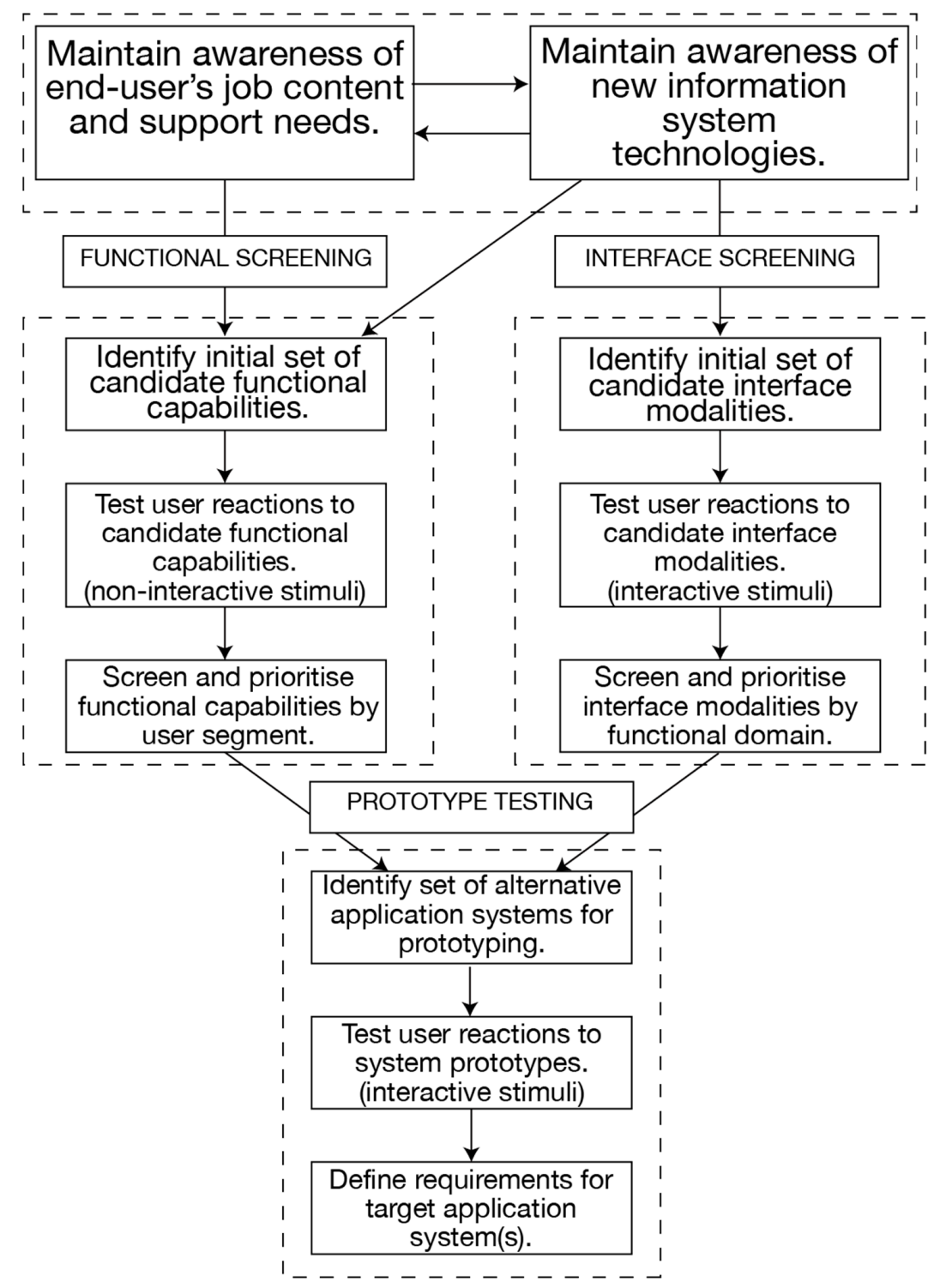

Figure 4. Generic user acceptance testing procedure as created by Davis. It highlights the selection of new support systems that have the highest probability of acceptance by users [34].

\subsection{Unified Theory of Acceptance and Use of Technology (UTAUT)}

Venkatesh et al. [35] developed this model as an extension of Davis' [34] TAM. The UTAUT model (Figure 5) illustrates the relationship between the four primary determinants of intention and usage 
(on the left) and behaviour intention and use behaviour. The model also details key mediating factors in this relationship (on the bottom). Performance expectancy can be impacted by gender and age, and is considered in UTAUT as a determinant of intention to use.

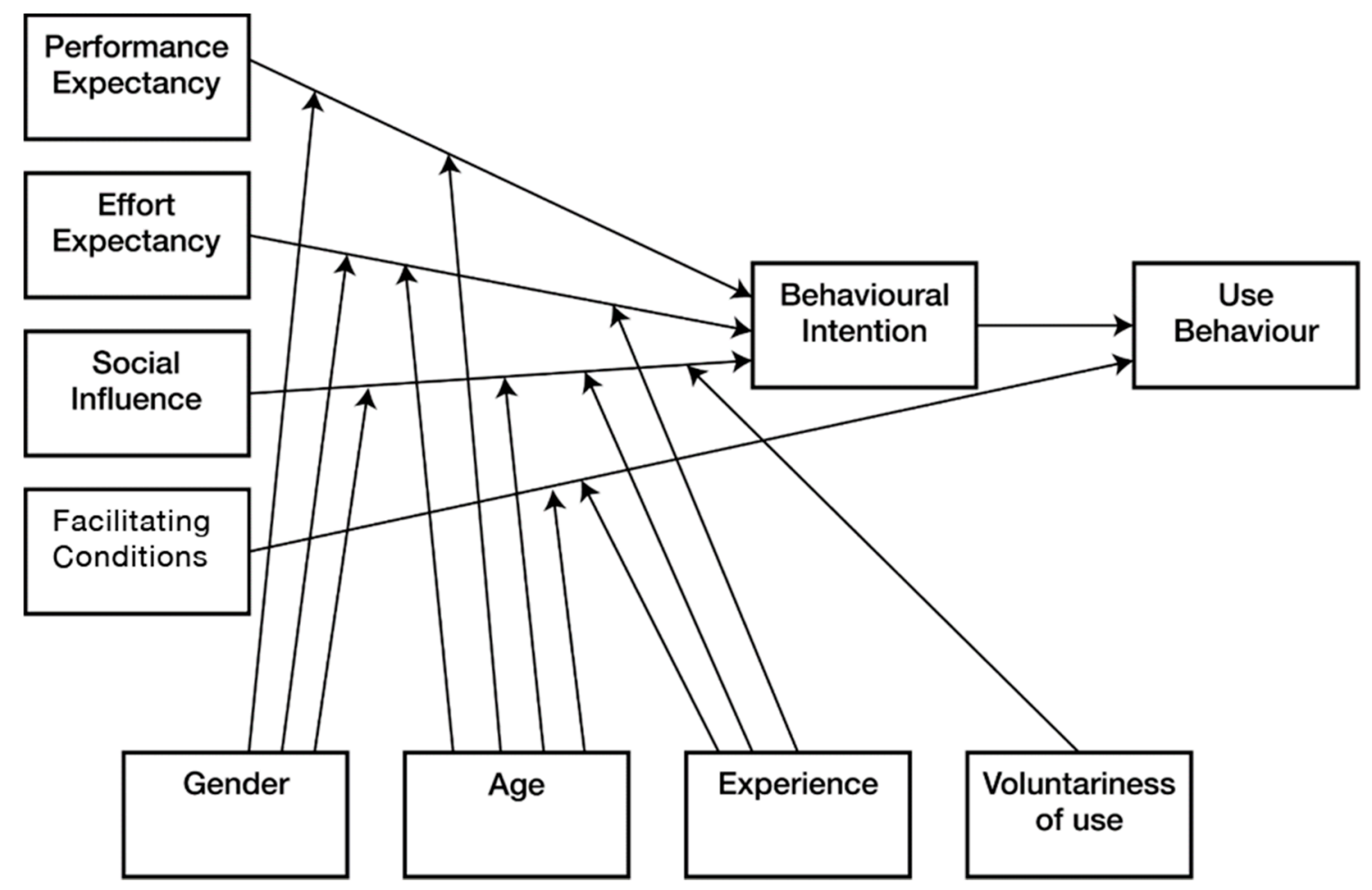

Figure 5. Unified theory of acceptance and use of technology (UTAUT) model as introduced by Venkatesh et al. [35] expands further on technology acceptance models by including four primary determinants of intention and usage (performance expectancy, effort expectancy, social influence, facilitating conditions).

The constructs in UTAUT are detailed as follows with examples:

- Performance expectancy-e.g., I would find the system useful in my job.

- Effort expectancy-e.g., It would be easy for me to become skilful at using the system.

- Attitude toward using technology-i.e., using the system is a bad/good idea.

- Social influence-e.g., People who influence my behaviour think that I should use the system.

- Facilitating conditions-e.g., I have the resources necessary to use the system.

- Self-efficacy - e.g., I could complete a job or task using the system ... if I could call someone if I got stuck.

- Anxiety-e.g., It scares me to think that I could lose a lot of information using the system by hitting a wrong key.

- Behavioural intention to use the system-e.g., I intend to use the system in the next number of months.

\subsection{Almere TAM}

Heerink et al. [30] proposed the Almere TAM specifically for robot use by older adults. It builds on the UTAUT model [35] and includes the variables of perceived usefulness and perceived ease of use from Davis [34]. Heerink worked off the UTAUT, suggesting it was a better platform than traditional TAMs for exploring technology acceptance of robots by older adults, particularly in social environments. 
Heerink amended previous TAM constructs to a list of thirteen and proposed relationships between them, as detailed in Figure 6.

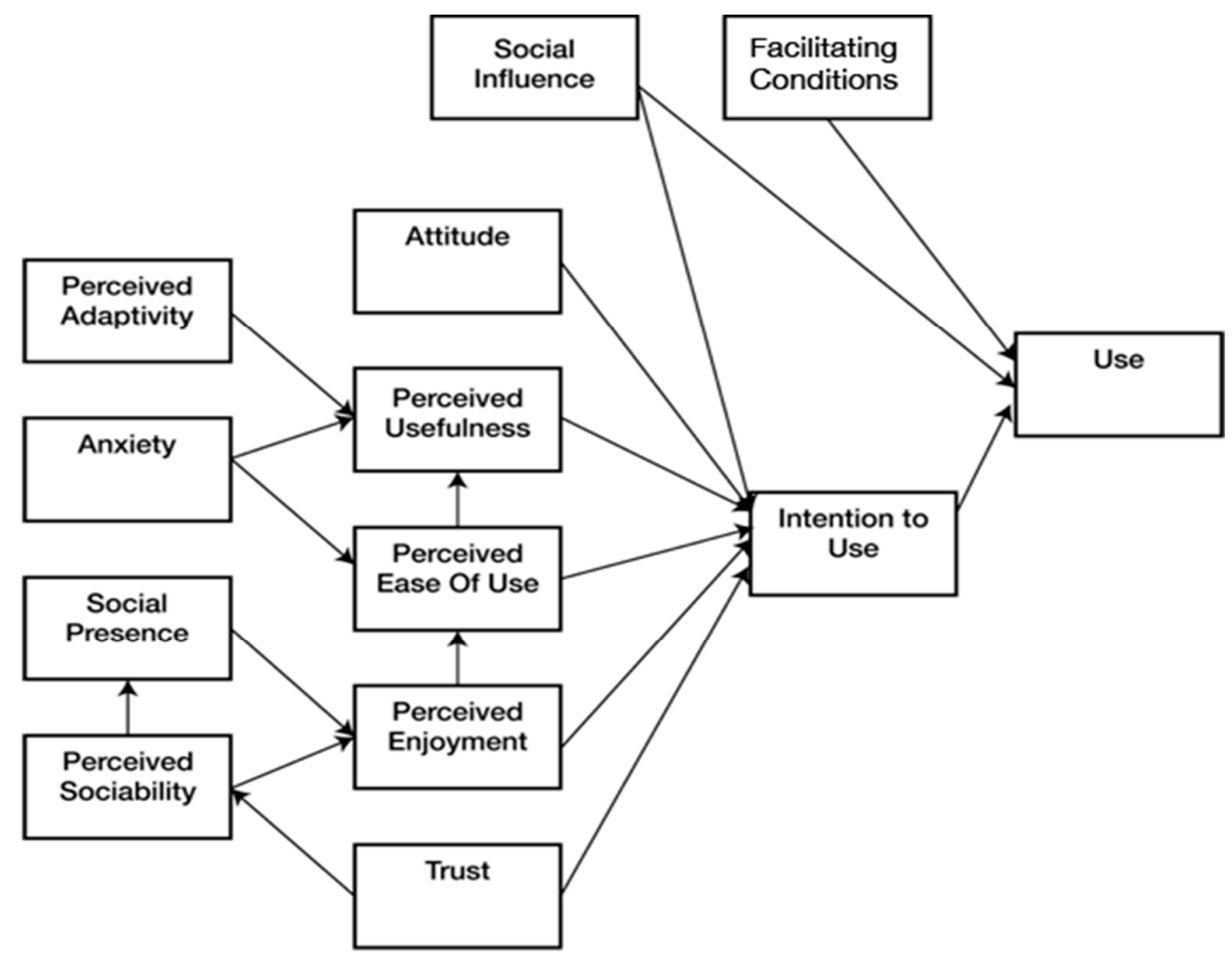

Figure 6. Almere TAM displaying the constructs leading to acceptance and use. A construct of note with this model is perceived adaptability, which affords consideration to the impact of ageing and change in condition or ability. This, in turn, supports modifiable elements to the technology in question [30].

Almere TAM constructs as described by Heerink [30]:

- Anxiety-anxious or emotional reactions when using the system

- Attitude-positive or negative feelings about the application of the technology

- Facilitating conditions-objective factors in the environment that facilitate using the system

- Intention to use-The outspoken intention to use the system over a longer period of time

- Perceived adaptability - the perceived ability of the system to be adaptive to the changing needs of the user

- Perceived enjoyment-feelings of joy or pleasure by the user associated with the use of the system

- Perceived ease of use - the degree to which the user believes that using the system would be free of effort

- Perceived sociability-the perceived ability of the system to inform sociable behaviour

- Perceived usefulness - the degree to which a person believes that using the system would enhance his or her daily activities

- Social influence-the user's perception of how people who are important to them think about him/her using the system

- Social presence-the experience of sensing a social entity when interacting with the system

- Trust - the belief that the system performs with integrity and reliability

- Use-the actual use of the system over a longer period of time 
Heerink et al. [30] detailed that the model was validated and tested. Smarr et al. [10] indicated a positive critique of the model stating that it was a succinct self-report quantitative measure of older adults' technology acceptance and that it is applicable to several assistive social agents.

\subsection{Senior Technology Acceptance Model (STAM)}

Chen and Chan [31] developed the senior technology acceptance model (STAM) to consider older adults and age-related aspects not covered by previous TAMs. This model proposes that physical, psychological and social characteristics associated with ageing affect older adult interactions with technologies, specifically in the context of gerontechnology.

STAM is also an evolution of UTAUT [35]. Figure 7 details STAM, including the constructs and their relationship with perceived usefulness, usage behaviour and perceived ease of use, and their relationship with attitude towards use. In the model, dashed lines denote less significant paths in the model. STAM was developed following a 12-month study of user behaviour with a wide range of electronic products.

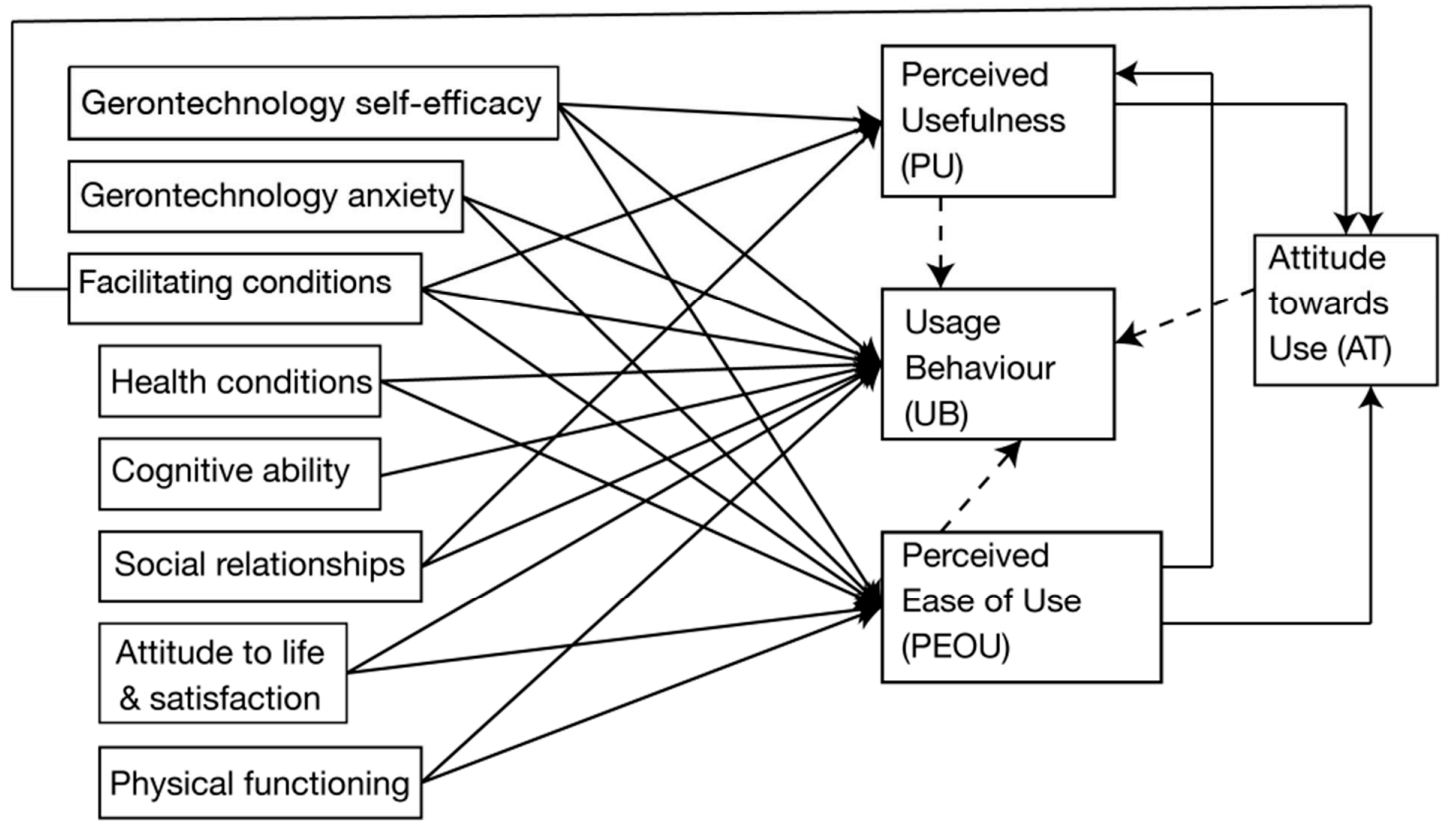

Controlled variables: age, gender, education level, and economic status

Figure 7. Senior technology acceptance model (STAM). Chen and Chan propose that physical, psychological, and social characteristics associated with ageing may affect how an older adult interacts with technology and devices [31].

\section{Discussion}

\subsection{TAMs and Assistive Technology Models}

This commentary discusses technology acceptance models and their relation to older adults and assistive exoskeleton design. Other AT models (e.g., HAAT [18], MPT [28]) are intended to be used to assess the suitability of assistive devices for people with disabilities in the context of the activities in which they engage [37]. However, as a means to optimise and enhance adoption of exoskeletons by older adults, there is a need to develop a broader technology acceptance model that gauges perceptions and long-term use experiences by older adults. To date, a literature review has not revealed a technology acceptance model that gauges acceptance of exoskeletons. It is predicted that exoskeletons may be common devices seen and worn by people in everyday settings in the coming years [9]. 
Cook and Polgar [18] suggest that older adults in the age group of 65-70 have some prior use and knowledge of technology; however, they may express some fear with regard to learning a new technology, e.g., fear of breaking it, or the cost of repairs if they are responsible for damaging it. This can be exacerbated by a decline in sensory, motor or cognitive skills as ageing progresses. For this reason, TAMs may be an informative tool that broadens the acceptance and use of new technology-assistive devices such as exoskeletons.

Table 1 compares three shortlisted technology acceptance models by key evaluation criteria. As displayed, older adults' acceptance is evaluated by two models, Almere and STAM; however, Almere is the only model that considers adaptability and future thinking.

Table 1. Relationship matrix of technology acceptance models and older adults.

\begin{tabular}{cccc}
\hline & $\begin{array}{c}\text { Unified Theory of Acceptance of } \\
\text { Technology (UTAT) }\end{array}$ & Almere Model & $\begin{array}{c}\text { Senior Technology } \\
\text { Acceptance Model (STAM) }\end{array}$ \\
\hline $\begin{array}{c}\text { Evaluated older adult perceptions } \\
\text { and user of technology }\end{array}$ & $x$ & $\checkmark$ & $\checkmark$ \\
\hline $\begin{array}{c}\text { Affords adaptability of } \\
\text { technologies and future thinking }\end{array}$ & $x$ & $\checkmark$ & $x$ \\
\hline Specific to robots/social agents & $x$ & $\checkmark$ & $\times$ \\
\hline $\begin{array}{c}\text { Tested with users in social } \\
\text { environments }\end{array}$ & $x$ & & $\times$ \\
\hline
\end{tabular}

The evaluation methods used to prescribe assistive technologies are, in general, evaluated between users and healthcare professionals. This can present challenges to designers in understanding and applying the expertise of other disciplines. With that in mind, it is important to understand, and be guided by, outside disciplines to broaden user requirements for design. There is a need to evaluate further measures required to optimise acceptance and use by older adults [18]. This is where the constructs of an exoskeleton TAM could potentially bridge the gap of understanding between AT models and user-centred design. In turn, this presents challenges and opportunities for designers to develop a more tailored model that can measure acceptance and optimism to adopt assistive robots, and specifically exoskeletons.

\subsection{User-Centred Design of Assistive Exoskeletons}

Exoskeletons, when deployed as assistive robots for older adults or users with motor impairments, are intended to support the user's independence. The ultimate aim is to design assistive robots that enhance the user's capacity to perform and engage in daily activities, rather than replacing or undermining their abilities. The review of TAMs in Section 2 detailed the importance of usability across several of the constructs, especially for gerontechnology applications. High usability requires the application of user-centred design methodologies, placing, in this case, the older adult at the centre of the design process, often including them as co-designer.

Older adults believe that learning to use new technologies is important to avoid feeling alienated from society [12]. They may also feel unable to cope with technology today [38]. However, assistive robot usage can carry the stigma of being dependent or declining in abilities, with older adults perceiving such stigma as unacceptable; thus, it presents a barrier to technology adoption [17,31]. User-centred design can also be used to de-stigmatise technologies, resulting in a greater probability of acceptance [18]. Motivation to use technologies can be further enhanced when the technology offers some alternative uses or functionalities aside from those related to healthcare or the provision of assistance [17].

\subsection{Practical Approaches to User-Centred Design of Exoskeletons}

The international standard ISO 13482 [26] details fundamental safety requirements for the design of exoskeletons, but it does not explicitly detail user-centred design requirements. A number of 
authors offer user-centred design principles for older adults [38,39], but there is very little by way of specific guidance for exoskeletons, particularly for older adult users. Norman [40] states how everyday people will learn to use new generation intelligent devices by trial and error, hence, they need to be easy and comfortable to use. Charness and Jastrzembski [23] state the importance of comfort, safety and efficiency in the design of products and processes for older adults to fundamentally improve quality of life and ADLs [15]. Older adults have a unique perspective on accepting and using assistive robots. Despite an acceptance of and curiosity about new technologies, they require extended time and practice in order to achieve competencies and autonomy of use [41]. Guidance on usability testing of older adults [42] is also offered, again highlighting the unique requirements older adults have to design. However, there is still a gap in user-centred design guidance for assistive robots, in particular exoskeletons for older adults. A variety of research methods may be used to address this knowledge gap to explore user design requirements with respect to assistive robots, from quantitative methods [43] such as questionnaires, to qualitative methods such as semi-structured interviews, and observation in participants' natural settings [44]. Direct involvement of older adult users is crucial to successfully drive the user-centred exoskeleton design process, maximising the potential for uptake and acceptance [39,45-47]. This enquiry could reveal insight and new knowledge that creates a new technology acceptance model. This may be an adaptation of Almere or STAM, or a new model that measures more specific features of exoskeletons, use such as cost, control of the exoskeleton, and acceptance of an additional device such as an exoskeleton and crutch.

\section{Conclusions}

This article makes an important contribution to the topic of user-centred design of exoskeletons and prospective approaches for studying technology acceptance of such devices by older adults. This commentary summarises the evolution of TAMs relative to gerontechnology applications. It discusses the importance of AT models to assessing the suitability of devices for a person with a disability. A clear outcome of the research is the need for empirical research into older adults' use and perceptions of exoskeleton technologies to further our understanding of theoretical and design factors that affect their adoption.

We note that there are relatively few TAM assessment methods available. Those outlined here are somewhat general with respect to the acceptance of technology as a whole. This commentary identified a preference for the Almere and STAM models for application to technology use by older adults. There is a requirement to develop a TAM that specifically evaluates the acceptance criteria and expectations of older adults using exoskeletons. In particular, qualitative studies of technology acceptance can be very beneficial in this respect.

A central conclusion from this commentary is that there is a distinct lack of user-centred design guidance for exoskeletons, and specifically for older adults. This is a barrier to the development of user-appropriate and user-friendly concepts that are needed to grow the acceptance and desirability of these concepts in the market.

Acknowledgments: This research was completed as part of the XoSoft project, which has received funding from the European Union's Horizon 2020 framework programme for research and innovation under grant agreement number 688175. The funding agency played no role in the writing of the manuscript.

Conflicts of Interest: The authors declare no conflict of interest.

\section{References}

1. Active and Assisted Living Joint Programme (AAL). Demographic Change Ageing Begins at Birth. 2016. Available online: http:/ / www.aal-europe.eu/about/demographic-change/ (accessed on 22 August 2017).

2. WHO. World Report on Disability. 2011. Available online: http://www.who.int/disabilities/world_report/ 2011/report.pdf (accessed on 15 November 2017).

3. Bedaf, S.; Huijnen, C.; van den Heuvel, R.; de Witte, L. Robots supporting care for elderly people. In Robotic Assistive Technologies; CRC Press: Boca Raton, FL, USA, 2017; Chapter 9, pp. 309-332. 
4. Borisoff, J.; Khalili, M.; Ben Mortenson, W.; Van der Loos, H.F.M. Exoskeletons as an assistive technology for mobility and manipulation. In Robotic Assistive Technologies; CRC Press: Boca Raton, FL, USA, 2017; Chapter 6, pp. 179-218.

5. Lauer, E.A.; Houtenville, A.J. Annual Disability Statistics Compendium: 2016. Available online: https:/ / disabilitycompendium.org/sites/default/files/user-uploads /2016\%20Annual\%20Disability\% 20Statistics\%20Compendium.pdf (accessed on 15 November 2017).

6. European Commission. Communication from the Commission to the European Parliament, the Council, the European Economic and Social Committee and the Committee of the Regions European Disability Strategy 2010-2020: A Renewed Commitment to a Barrier-free Europe. 2010. Available online: http: / / eur-lex.europa.eu/legal-content/EN/ALL/?uri=celex:52010DC0636 (accessed on 10 December 2017).

7. Manini, T.M. Mobility decline in old age: A time to intervene. Available online: https://www.ncbi.nlm.nih. gov/pmc/articles/PMC3530168/ (accessed on 31 October 2017).

8. Research and Markets. Wearable Robots, Exoskeleton: Market Shares, Strategies, and Forecasts, Worldwide, 2016-2021. Available online: http://www.researchandmarkets.com/reports/3700034/wearablerobotsexoskeleton-market-shares (accessed on 25 August 2017).

9. Young, A.; Ferris, D. State-of-the-art and future directions for lower limb robotic exoskeletons. IEEE Trans. Neural Syst. Rehabilit. Eng. 2016, 25, 171-182. [CrossRef] [PubMed]

10. Smarr, C.A.; Mitzner, T.L.; Beer, J.M.; Prakash, A.; Chen, T.L.; Kemp, C.C.; Rogers, W.A. Domestic robots for older adults: Attitudes, preferences, and potential. Int. J. Soc. Robot. 2013, 6, 229-247. [CrossRef] [PubMed]

11. Bemelmans, R.; Gelderblom, G.J.; Jonker, P.; de Witte, L. Socially assistive robots in elderly care: A systematic review into effects and effectiveness. J. Am. Med. Dir. Assoc. 2012, 13, 114-120. [CrossRef] [PubMed]

12. Wu, Y.H.; Damnée, S.; Kerhervé, H.; Ware, C.; Rigaud, A.S. Bridging the digital divide in older adults: A study from an initiative to inform older adults about new technologies. Clin. Interv. Aging 2015, 10, 193-201. [CrossRef] [PubMed]

13. Nathan, S. Power Dressing: Why It's Exoskeleton Time. The Engineer. Available online: https://www. theengineer.co.uk/issues/december-digi-issue/power-dressing-why-its-exoskeleton-time/ (accessed on 23 August 2017).

14. Van der loos, H.F.M.; Reinkensmeyer, D.J.; Guglielmelli, E. Rehabilitation and health care robotics. In Handbook of Robotics; Springer: Berlin, Germany, 2008; p. 53.

15. Katz, S. Assessing self-maintenance: Activities of daily living, mobility, and instrumental activities of daily living. J. Am. Geriatr. Soc. 1983, 31, 721-727. [CrossRef] [PubMed]

16. Pigliautile, M.; Tiberio, L.; Mecocci, P.; Federici, S. The Geriatrician. In Assistive Technology Assessment Handbook; (Rehabilitation Science in Practice Series); CRC Press: Boca Raton, FL, USA; London, UK; New York, NY, USA, 2012; Chapter 13, pp. 269-299.

17. Wu, Y.H.; Wrobel, J.; Cornuet, M.; Kerhervé, H.; Damnée, S.; Rigaud, A.S. Acceptance of an assistive robot in older adults: A mixed-method study of human-robot interaction over a month period in the Living Lab setting. Clin. Interv. Aging 2014, 9, 801-811. [CrossRef] [PubMed]

18. Cook, A.; Polgar, J. Assistive Technologies: Principles \& Practices; Elsevier/Mosby: St. Louis, MO, USA, 2015.

19. Pazzaglia, M.; Molinari, M. The embodiment of assistive devices-From wheelchair to exoskeleton. Phys. Life Rev. 2016, 16, 163-175. [CrossRef] [PubMed]

20. Broadbent, E.; Stafford, R.; MacDonald, B. Acceptance of healthcare robots for the older population: Review and future directions. Int. J. Soc. Robot. 2009, 1, 319-330. [CrossRef]

21. Hill, D.; Holloway, C.S.; Morgado Ramirez, D.Z.; Smitham, P.; Pappas, Y. What are user perspectives of exoskeleton technology? A literature review. Int. J. Technol. Assess. Health Care 2017, 33, 160-167. [CrossRef] [PubMed]

22. Wolff, J.; Parker, C.; Borisoff, J.; Mortenson, W.B.; Mattie, J. A survey of stakeholder perspectives on exoskeleton technology. J. Neuroeng. Rehabilit. 2014, 11, 1-10. [CrossRef] [PubMed]

23. Charness, N.; Jastrzembski, T.S. Gerontechnology. In Future Interaction Design II; Saariluoma, P., Isomaki, H., Eds.; Springer-Verlag: London, UK, 2009; pp. 1-29, ISBN 978-1-84800-300-2.

24. Harrington, T.L.; Harrington, M.K. Gerontechnology Why and How; Herman Bouma Foundation of Gerontechnology: Eindhoven, The Netherlands, 2000.

25. Randolph, A.B.; Hubona, G.S. Organizational and individual acceptance of assistive interfaces and technologies. In Human-computer Interaction and Management Information Systems: Applications; M.E. Sharpe, Inc.: Armonk, NY, USA; London, UK, 2006; Volume 6, pp. 379-400. 
26. International Organization for Standardization. ISO 13482: Robots and robotic devices—Safety Requirements for Personal Care Robots. 2014. Available online: https:/ / www.iso.org/standard/53820.html (accessed on 14 November 2017).

27. World Health Organisation. ICF: International Classification of Functioning, Disability and Health. Draft Practice Manual. Available online: http:/ / www.who.int/classifications / drafticfpracticalmanual2.pdf?ua=1 (accessed on 30 October 2017).

28. Federici, F.; Scherer, M.J. (Eds.) Assistive Technology Assessment Handbook; CRC Press: Boca Raton, FL, USA; New York, NY, USA, 2012.

29. Venkatesh, V.; Davis, F.D. A theoretical extension of the technology acceptance model: Four longitudinal field studies. Manag. Sci. 2000, 46, 186-204. [CrossRef]

30. Heerink, M.; Kröse, B.; Evers, V.; Wielinga, B. Assessing acceptance of assistive social agent technology by older adults: The almere model. Int. J. Soc. Robot. 2010, 2, 361-375. [CrossRef]

31. Chen, K.; Chan, A.H.S. Gerontechnology acceptance by elderly Hong Kong Chinese: A senior technology acceptance model (STAM). Ergonomics 2014, 57, 635-652. [CrossRef] [PubMed]

32. Ajzen, I.; Fishbein, M. Understanding Attitudes and Predicting Social Behaviour; Prentice-Hall: Englewood Cliffs, NJ, USA, 1980.

33. Ajzen, I. From intentions to actions: A theory of planned behavior. In Action Control: From Cognition to Behavior; Kuhl, J., Beckmann, J., Eds.; Springer: Berlin, Germany, 1985.

34. Davis, F.D. A Technology Acceptance Model for Empirically Testing New End-User Information Systems: Theory and Results. Ph.D. Thesis, Massachusetts Institute of Technology, MA, USA, 20 December 1985.

35. Venkatesh, V.; Morris, M.G.; Davis, G.B.; Davis, F.D. User acceptance of information technology: Toward a unified view. MIS Q. 2003, 27, 425-478. [CrossRef]

36. Davis, F.D. Perceived usefulness, perceived ease of use, and user acceptance of information technology. MIS Q. 1989, 13, 319-340. [CrossRef]

37. Lenker, J.A.; Paquet, V.L. A review of conceptual models for assistive technology outcomes research and practice. Assist. Technol. 2003, 15, 1-15. [CrossRef] [PubMed]

38. Newell, A.F. Design and the Digital Divide-Insights from 40 Years in Computer Support for Older and Disabled People; Morgan \& Claypool: London, UK, 2011.

39. Fisk, A.D.; Rogers, W.A.; Charness, N.; Czaja, S.J.; Sharit, J. Design for Older Adults—Principles and Creative Human Factor Approaches; CRC Press: Boca Raton, FL, USA, 2004.

40. Norman, D.A. The Design of Future Things; BasicBooks: New York, NY, USA, 2007.

41. Farage, M.A.; Miller, K.W.; Ajayi, F.; Hutchins, D. Design principles to accommodate older adults. Glob. J. Health Sci. 2012, 4, 2-25. [CrossRef] [PubMed]

42. Rubin, J.; Chisnell, D. How to plan, design and conduct effective tests. In Handbook of Usability Testing, 2nd ed.; Wiley: Indianapolis, IN, USA, 2008.

43. De Looze, M.; Bosch, T.; Krause, F.; Stadler, K.; O'Sullivan, L.W. Exoskeletons for industrial application and their potential effects on physical work load. Ergonomics 2016, 59, 671-681. [CrossRef] [PubMed]

44. Blomberg, J.; Giacomi, J.; Mosher, A.; Swenton-Wall, P. Ethnographic field methods and their relation to design. In Participatory Design: Principles and Practices; CRC Press: Boca Raton, FL, USA, 1993; pp. 123-155.

45. Pirkl, J.J. Transgenerational Design_Products for an Ageing Population; Van Nostrand Reinhold: New York, NY, USA, 1994.

46. Shah, S.G.S.; Robinson, I.; Al Shawi, S. Developing medical device technologies from users' perspectives: A theoretical framework for involving users in the development process. Int. J. Technol. Assess. Health Care 2009, 25, 514-521. [CrossRef] [PubMed]

47. O'Sullivan, L.; Power, V.; de Eyto, A.; Bauer, C.; Nikamp, C.; Schülein, S.; Müller, J.; Ortiz, J. Exploring User Requirements for a Lower Body Soft Exoskeleton to Assist Mobility. In Wearable Exoskeleton Systems: Design, Control and Applications; Bai, S., Virk, G., Sugar, T., Eds.; IET: Stevenage, UK, 2017.

(C) 2018 by the authors. Licensee MDPI, Basel, Switzerland. This article is an open access article distributed under the terms and conditions of the Creative Commons Attribution (CC BY) license (http:/ / creativecommons.org/licenses/by/4.0/). 